\title{
FUNDAMENTOS DA GESTÃO DA INFORMAÇÃO PROJETUAL EM CURSO DE ARQUITETURA E URBANISMO ${ }^{1}$
}

\section{BASICS INFORMATION DESIGN MANAGEMENT IN ARCHITECTURE AND URBAN PLANNING UNDERGRADUATION COURSE}

\author{
Rejane de Moraes Rêgo \\ Universidade Federal de Pernambuco (UFPE) \\ rejane.rego@ufpe.br \\ Patrícia Porto Carreiro \\ Universidade Federal de Pernambuco (UFPE) \\ patricia carreiro@yahoo.com.br
}

\begin{abstract}
Resumo
O artigo relata a experiência didático-pedagógica realizada na disciplina "Informática aplicada à Arquitetura, Urbanismo e Paisagismo II (InfoAU-II)" do Curso de Arquitetura e Urbanismo - Universidade Federal de Pernambuco. Considerando que apesar do uso de Tecnologias de Informação e Comunicação (TICs) na projetação em arquitetura e urbanismo estar sedimentado, observam-se dificuldades na adoção de gestão da informação por profissionais, acarretando em retrabalho, perda de informações e comprometimento do trabalho colaborativo. Nesse contexto, a disciplina tem como objetivo apresentar a projetação como um processo colaborativo e de gestão de informação. Baseada em princípios da pesquisa-ação, a experiência foi bem avaliada pelos estudantes, em todos os semestres de sua aplicação, os quais registraram mudança de procedimento na gestão da informação, melhoria do compartilhamento das informações projetuais e o consequente aumento de produtividade. Contudo, assinalaram a dificuldade de manter os procedimentos definidos pelas diretrizes de gestão. A experiência tem contribuído para que estudantes de períodos iniciais compreendam a projetação como um processo de gestão da informação e explicitado a importância da rastreabilidade e compartilhamento de informação.
\end{abstract}

Palavras-chave: Gestão da informação. Projetação. Arquitetura. Urbanismo. Ensino.

\begin{abstract}
The article reports the didactic and pedagogical experience that took place in the course "Informatics applied to Architecture, Urbanism and Landscape II (InfoAU-II)", of the Architecture and Urbanism undergraduation course Federal University of Pernambuco. Although the use of Information and Communication Technologies (ICTs) in architecture and urbanism design to be established, it is possible to verify difficulties in adopting information management by professionals, resulting in rework, loss of information and time, disturbing the collaborative work. In this context, the course aims to present the design process as a collaborative and information management activity. Based in action-research methodological principles, it was well evaluated by students in all semesters' application. The students recorded procedure changes in their information management, improving the information sharing process and, consequentially, increase in productivity. However, they point out their difficulty of keeping the defined in the management guidelines. The experience has contributed to students in earlier periods understand the design as an information management process and show the significance of traceability and information sharing.
\end{abstract}

Keywords: Information management. Designing. Architecture. Urban Planning. Teaching.

\footnotetext{
${ }^{1}$ RÊGO, R. M.; PORTO CARREIRO, P. Fundamentos da Gestão de Informação Projetual em Curso de Arquitetura e Urbanismo. In: ENCONTRO BRASILEIRO DE TECNOLOGIA DE INFORMAÇÃO E COMUNICAÇÃO NA CONSTRUÇÃO, 7., 2015, Recife. Anais... Porto Alegre: ANTAC, 2015.
} 


\section{INTRODUÇÃO}

O artigo apresenta a experiência didático-pedagógica desenvolvida em disciplina obrigatória da matéria "Informática aplicada à Arquitetura e Urbanismo (InfoAU)" do Curso de Arquitetura e Urbanismo da Universidade Federal de Pernambuco - UFPE, inserida no contexto do novo Projeto Pedagógico de Curso, em implantação desde 2010 (PPC2010).

Do ponto de vista teórico-metodológico, o PPC2010 propõe que na formação acadêmica o estudante desenvolva leitura e compreensão crítica da projetação, sob as óticas integradas da paisagem, do urbanismo e da arquitetura, em uma educação proativa, flexível, vivenciada e de qualidade. Para tanto, se fundamenta em três diretrizes principais, de modo a possibilitar a formação proposta, ou seja: (a) a indissociabilidade do ato projetual para paisagem/cidade/edifício; (b) a interdisciplinaridade e (c) a aprendizagem baseada em problemas (ABP).

Do ponto de vista profissional, o PPC2010 possibilita integrar a vivência da cidade à educação formal do arquiteto/urbanista, por meio de uma formação voltada a uma realidade socioambiental, concretizada por exercícios projetuais pautados nas necessidades de comunidades locais, buscando-se melhorar a forma de viver dos indivíduos e, por consequência, a intervenção sociocultural do arquiteto-urbanista na contemporaneidade. Assim, além de reforçar a importância do trabalho desse profissional, incrementa um novo perfil como gestor de processos, não só como coordenador dos vários profissionais envolvidos na execução de um projeto, como também, priorizando a gestão do próprio processo projetual.

Como parte do grupo de matérias instrumentais, responsáveis por viabilizar técnicas ou instrumentos práticos no ato projetual, a matéria de InfoAU é constituída por três disciplinas obrigatórias e por cinco disciplinas eletivas.

A disciplina em foco é oferecida no terceiro período e denomina-se "Informática aplicada à Arquitetura, Urbanismo e Paisagismo II (InfoAU-II), tem 15 horas/aula, sendo a segunda entre as três obrigatórias. Possuindo ementa genérica para adequar-se à dinâmica de evolução das tecnologias de informação e comunicação (TICs) aplicadas à arquitetura e urbanismo, InfoAUII tem como principal eixo de conteúdo a Gestão da Informação Projetual, como reforço aos procedimentos de comunicação e colaboração iniciados desde o primeiro semestre do Curso na primeira obrigatória denominada InfoAU1. ${ }^{2}$

Compreendendo-se que a adoção de procedimentos básicos de gestão da informação digital na projetação em arquitetura e urbanismo ainda é falha, confusa e inadequada, apesar de o uso TICs estar sedimentado, a disciplina busca sensibilizar e orientar os estudantes com vista à melhoria de produtividade, na reusabilidade e no compartilhamento de informações. Tem por objetivo a compreensão por parte do estudante da natureza da projetação como processo colaborativo e de gestão de informação.

Para tanto, apoia-se nos pressupostos da ABP, que tem por eixo fundamental o deslocamento do aluno para o centro do processo educativo, dando-Ihe autonomia e responsabilidade pela aprendizagem. Um processo que se desenvolve por meio da identificação e análise de problemas, da capacidade de elaborar questões e procurar informações para ampliá-las e respondê-las, criando-se um ciclo onde novas questões são, naturalmente, levantadas, e novos processos de aprendizagem e de problematização são desenvolvidos (ARAÚJO; SASTRE, 1999).

\footnotetext{
2 Uma discussão mais detalhada pode ser encontrada em: PORTO CARREIRO, P.; RÊGO, R. M. Tecnologias de gestão, colaboração e comunicação no apoio ao ensino do processo projetual para construção de modelos multiescalas. In: ENCONTRO BRASILEIRO DE TECNOLOGIA DE INFORMAÇÃO E COMUNICAÇÃO NA CONSTRUÇÃO, 7., 2015, Recife. Anais... Porto Alegre: ANTAC, 2015. p. 1-7.
} 
A seguir, apresenta-se a experiência desenvolvida do semestre 2012.2 ao 2014.2, à qual foi sendo ajustada a partir da avaliação do processo e de seus resultados, com base em procedimentos metodológicos de pesquisa-ação (THIOLLENT, 1994).

\section{PROJETAÇÃO COMO PROCESSO DE GESTÃO DA INFORMAÇÃO}

Histórica e culturalmente a formação em arquitetura e urbanismo enfatiza a natureza criativa da projetação. Uma vez que a representação gráfica manual (desenhos) teve o papel de principal instrumento mediador no processo projetual (RÊGO, 2010), tornou-se comum privilegiar a atividade como um "fazer artístico".

Em que pese as diferentes abordagens sobre a projetação como sequência de atividades e tomada de decisão (ASIMOW, 1962), como processo lógico-matemático, passível de abstração sistematizável e implementação em artefatos computacionais (ALEXANDER, 1964; MITCHELL, 2008), como dualidade entre criatividade e racionalidade (JONES, 1970), como resolução de problemas mal definidos (SIMON, 1969, 1972), como reflexão-na-ação (SCHÖN, 1983, 2000), a compreensão do processo projetual em arquitetura e urbanismo como gestão da informação ainda é pouco disseminado.

Ozaka e Akin (2006) apud Ito (2007, p. 22) argumentam que no contexto computacional de projeto é necessário "considerar a projetação como geração de informação e da forma do objeto, incorporando continuidade e rastreabilidade das informações como parte do processo de projeto".

Para Meniru et al (2003) e Kalay (2006) também citados por Ito (2007, p. 20),

Um projeto de arquitetura é resultado da captação, organização e manipulação de informações, de tal forma que possam ser recuperadas e usadas pelo arquiteto, para produzir uma nova informação, simular e avaliar seus impactos. A informação é então usada para construção e percepção dos resultados da fase de projeto.

Já para Melhado e Agopyan (1995) e Ozaka e Akin (2006) apud Ito (2007, p. 22), "Projeto é informação e o desafio durante a sua fase de formulação, e uma das chaves da tarefa de projeto, é gerenciar a extração de informações úteis para antecipar e evitar erros potenciais nas soluções."

Contestando a natureza sequencial e segmentada em etapas da projetação em arquitetura, engenharia e construção (AEC), o

Setor da Construção Civil começou a dar maior importância ao projeto e sua relação com a produção, estreitando as relações entre os que pensavam projeto de produto e os que pensavam projeto do processo, dando origem a uma nova filosofia de projetar: o projeto simultâneo (SOUZA et al., 2005a apud Ito, 2007, p. 25)

Ito (2007, p. 25) esclarece que

o projeto simultâneo promove a integração do desenvolvimento do produto (necessidades e expectativas do cliente) com o desenvolvimento dos demais processos envolvidos, pela colaboração entre os diversos agentes envolvidos no processo de projeto.

O processo de projeto em ambiente computacional favorece e ao mesmo tempo exige o reconhecimento de sua natureza como gestão da informação. A formação em arquitetura e urbanismo na atualidade não pode negligenciar essa visão, sob pena de provocar uma lacuna cujas repercussões podem comprometer a inserção do profissional no mercado de trabalho e a subutilização de potenciais abordagens e ferramentais projetuais computacionais. 
Uma vez identificada uma transição de paradigma projetual e apesar da consolidação do debate nacional sobre a educação projetual arquitetônica no cenário das transformações provocadas pelas tecnologias digitais, ainda há muitos aspectos que têm sido pouco aprofundados, em grande parte de cursos de arquitetura e urbanismo, como é o caso da projetação em ambiente de Modelagem de Informação da Construção (BIM). Considera-se que o emprego de programas computacionais identificados como "programas BIM" para trabalhos, apenas, de representação projetual, não pode ser referendado como a compreensão adequada do conceito BIM, de sua abrangência e consequente transformação no ato de projetar, e sim, uma subutilização desta abordagem projetual.

A projetação baseada no conceito de BIM requer habilidades e conhecimentos específicos que devem ser construídos na educação projetual. Sobre essa questão Flório (2007, p. 4) afirma:

No Curso de Arquitetura o maior problema reside em formar um profissional que seja capaz de entender claramente tanto as sucessivas etapas de criação, desenvolvimento e execução de projetos, como saber utilizar os melhores recursos para expressar e comunicar suas ideias sem perder criatividade e competência técnica. Atualmente a ênfase é dada apenas para a primeira, e relegada a segunda. Portanto, durante sua formação, o aluno deveria percorrer um caminho onde pudesse desenvolver competências e habilidades tanto do lado criativo, intuitivo e artístico, como do lado lógico, racional e técnico.

$\mathrm{Na}$ academia, lidar com informações projetuais digitais e adotar ferramentas computacionais adequadas para as diferentes etapas do processo projetual (para concepção, para representação projetual, para execução, para documentação de diferentes naturezas, etc.) requer do estudante o conhecimento de fundamentos de gestão da informação. Desse modo, se por um lado contribuirá para diminuir a perda da quantidade de informação gerada no próprio processo projetual e facilitará a rastreabilidade e compartilhamento da mesma com os demais atores/profissionais, por outro desenvolverá habilidades para trabalhar no contexto atual de projetação em ambiente computacional e incrementará seu perfil profissional como gestor de processos projetuais.

No mercado, a gestão de informação torna-se essencial ao gestor do processo projetual por garantir o êxito da execução do projeto, sendo fundamental para a colaboração e integração de informações entre vários atores/profissionais do processo projetual, tais como engenheiros, empreiteiros e construtores.

Trata-se essencialmente de reconhecer que o projeto é um processo interativo e coletivo, exigindo assim uma coordenação do conjunto das atividades envolvidas, compreendendo momentos de análise crítica e de validação das soluções, sem, no entanto, impedir o trabalho especializado de cada um dos seus participantes. Essa coordenação deve considerar aspectos do contexto legal e normativo que afeta cada empreendimento, estabelecer uma visão estratégica do desenvolvimento do projeto e levar devidamente em conta as suas incertezas. Uma metáfora para explicar o papel do arquiteto como coordenador de projeto é evocada por MELHADO; HENRY (2000): a do líder de uma banda de jazz, que ao mesmo tempo cria e participa da criação dos demais músicos do grupo, estimulando a sinergia de grupo dentro de um "processo criativo planejado".(MELHADO, 2001)

Melhado (2001, p. 71), ainda relata que Tapie (1999) ressalta a multidisciplinaridade e várias competências que envolve o processo projetual,

[...], afirmando que "a complexidade crescente dos empreendimentos de construção e urbanos, e as exigências de qualidade de produtos e serviços, colocadas pelos clientes e pelos empreendedores, favorecem a segmentação e a especialização, ao mesmo tempo em que obrigam permanentemente a 
arranjos de equipe para atender às necessidades de cooperação". [...] destaca a necessidade de uma gestão de competências, para responder à ampliação constante do conjunto de conhecimentos especializados de projeto, em substituição à simples divisão de tarefas e de responsabilidades que se baseia no bom relacionamento, familiaridade e amizade. Para o autor, "a gestão é o melhor recurso para responder às restrições atuais", para lidar com as contradições entre projetistas de formações disciplinares diversas e para fazer face à "incerteza de natureza múltipla (técnica, financeira, legal e política)" dos empreendimentos de construção e urbanos.

É no contexto anteriormente descrito que a experiência didático-pedagógica relatada nesse artigo busca inserção.

\section{DESCREVENDO A EXPERIÊNCIA DIDÁTICO-PEDAGÓGICA}

\subsection{Primeiras experimentações e seus resultados}

Em 2012.2 formulou-se uma proposta didático-pedagógica para InfoAU-II no contexto do PPC2010. Em sua primeira realização, a experiência iniciou-se com a aplicação de um questionário online, onde os estudantes foram perguntados sobre a maneira de lidar com as informações das disciplinas do curso. Em seguida, a partir da apresentação de diferentes compreensões (ASIMOW, 1962; ALEXANDER, 1964; JONES, 1970; NEWELL e SIMON, 1972; SIMON (1969), SCHÖN, 1983 e 2000), discutiu-se o processo projetual em arquitetura, urbanismo e paisagismo, destacando suas etapas e as informações geradas em cada uma. Como maneira de provocar os estudantes a refletirem sobre o seu processo projetual para resolução do problema colocado nas disciplinas de projeto do curso, solicitou-se que realizassem mapas mentais - MM.

Mapa mental é um método gráfico que facilita a visualização, a correlação e a recuperação de ideias, por meio de mapeamento e organização de informações não-lineares, visuais e de forma radial (BUZZAN, 1996), aliando as etapas, as informações trabalhadas e as disciplinas responsáveis por essas informações. O registro nos MM possibilitou que os estudantes revisitassem seu processo projetual e percebessem os diferentes tipos de informações envolvidas, como também a conexão das disciplinas com a atividade projetual.

Os MM foram elaborados manualmente (Figuras 1 e 2), seguindo as orientações específicas para esse tipo de registro do pensamento, como também foram realizados usando-se o software Prezi (Figuras 2 e 4). Essa ferramenta é destinada a apresentações, porém identificou-se que a mesma tem recursos que permitem: disposição de informações de várias mídias (especialmente imagens) em um espaço virtual dito ilimitado; flexibilidade de interconexão destas informações; inserção de informações sem nenhuma regra prévia e recuperação de informações orientada pelo usuário. Considerou-se, portanto, que estaria melhor adequado ao objetivo do que os programas típicos para elaboração de MM, os quais exigem uma categorização e hierarquização inicial da informação, para inserção e futura rastreabilidade. (PORTO CARREIRO; RÊGO, 2014) 
Figura 1 - Mapa mental do processo projetual elaborado manualmente

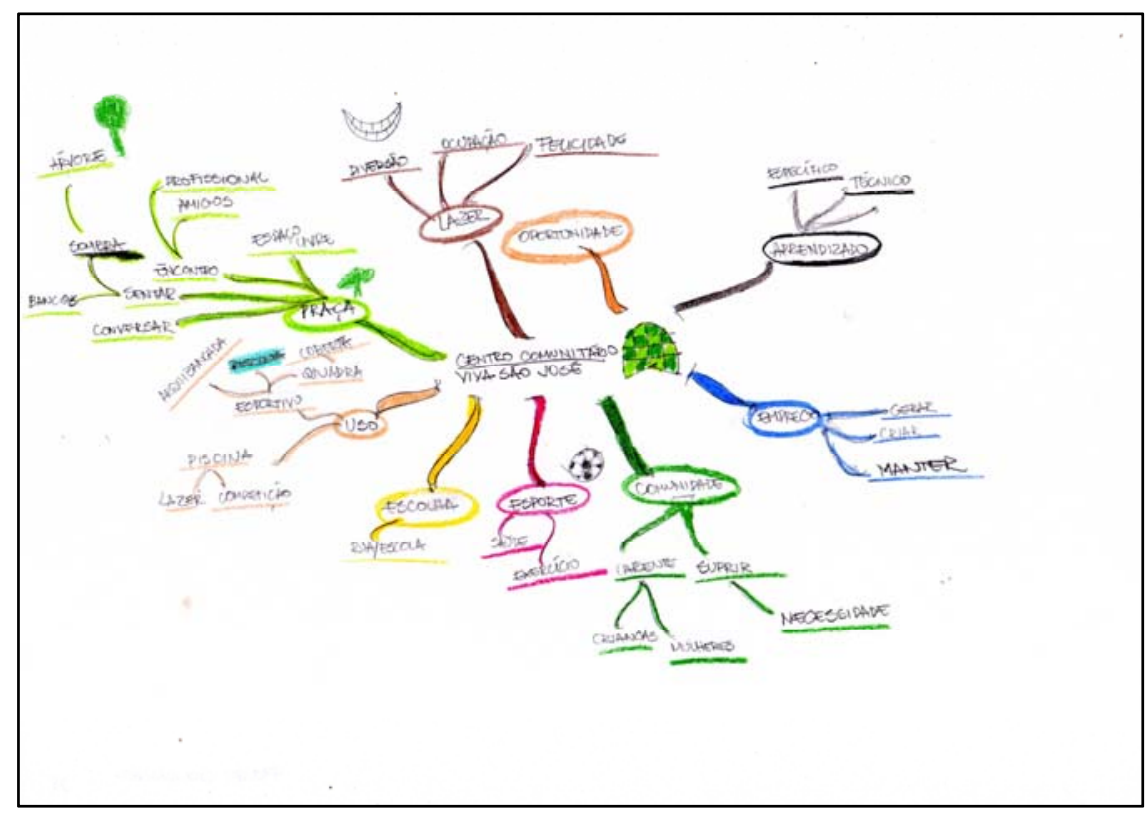

Fonte: Aluno Felipe Gonçalves - Disciplina de InfoAU-II, 2012

Figura 2 - Mapa mental do processo projetual elaborado manualmente

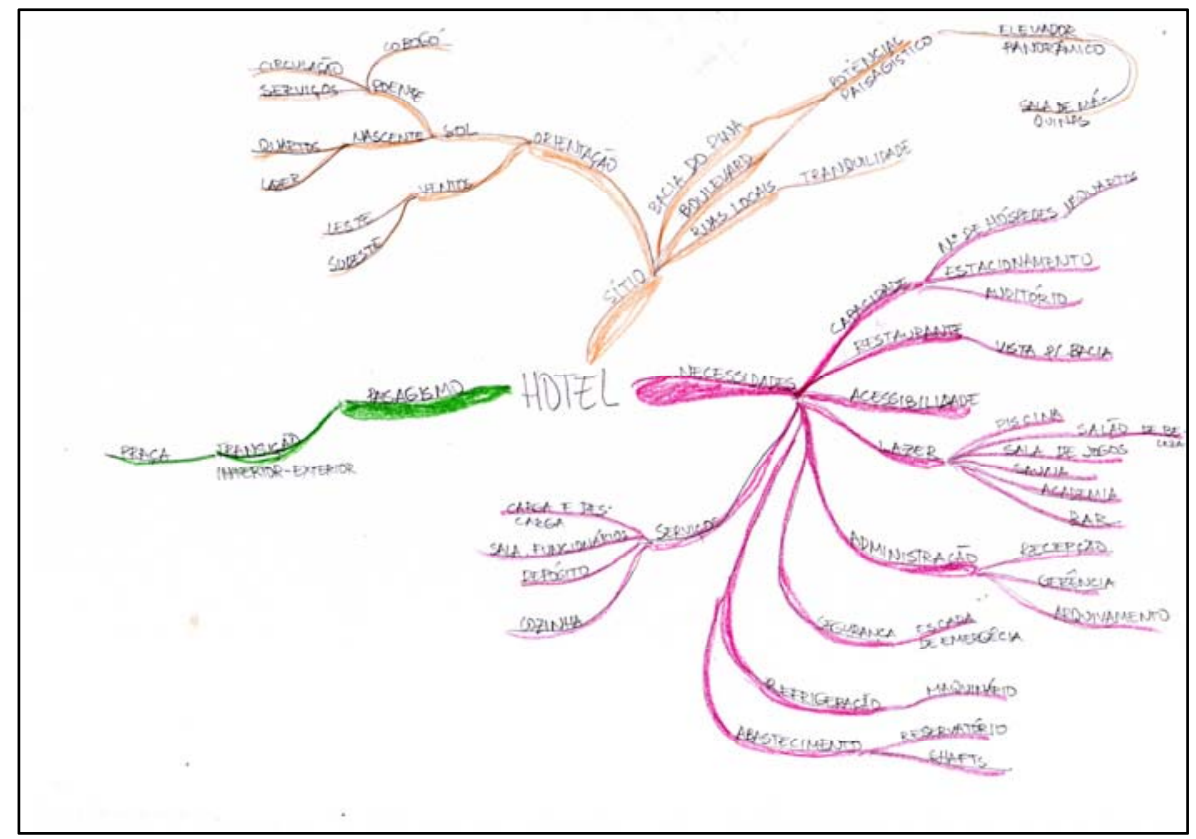

Fonte: Aluna Mariana Morais - Disciplina de InfoAU-II, 2012 
Figura 3 - Mapa mental do processo projetual elaborado no Prezi

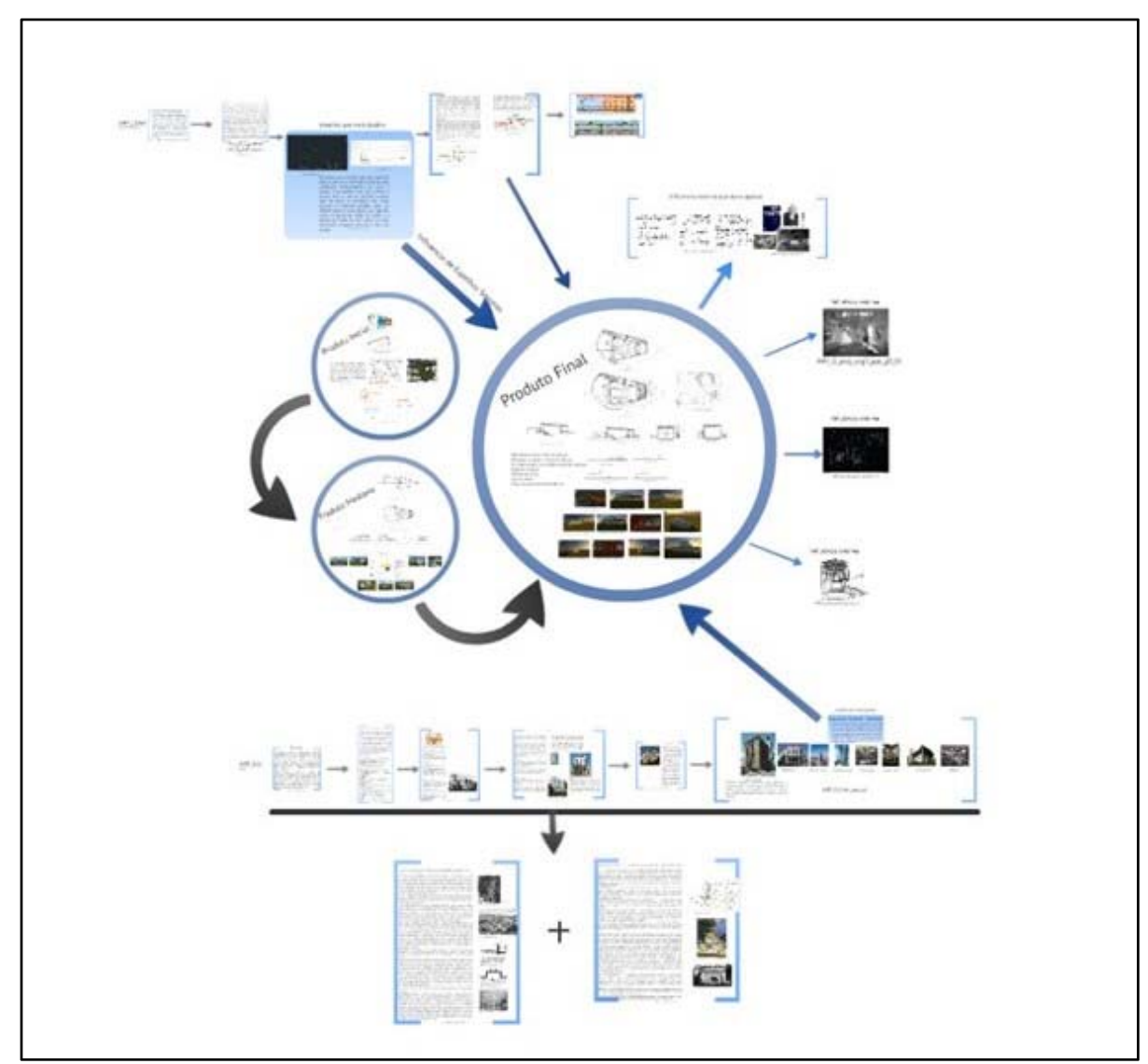

Fonte: Aluna Maria Cicília Melo - Disciplina de InfoAU-II, 2012

Figura 4 - Mapa mental do processo projetual elaborado no Prezi

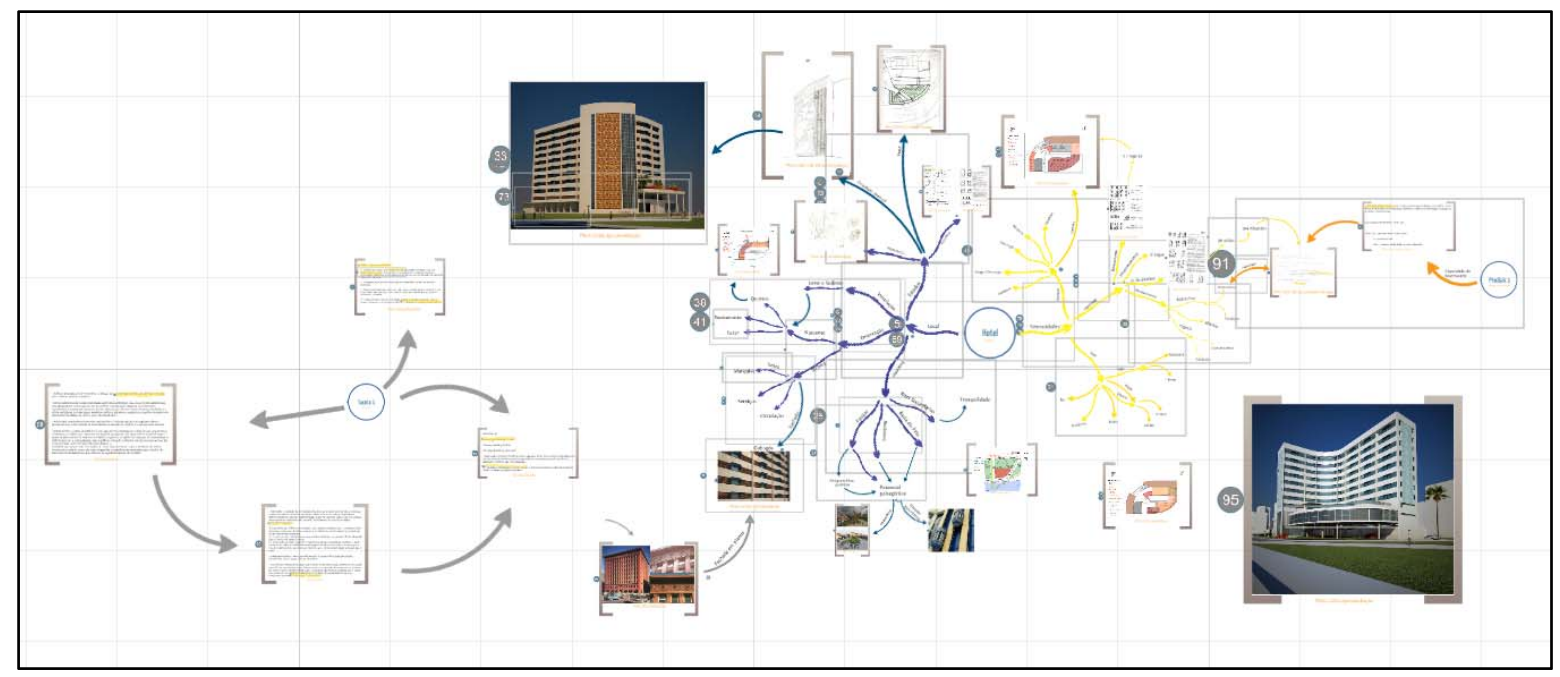

Fonte: Aluna Mariana Morais - Disciplina de InfoAU-II, 2012 
Com os MM, a experiência didático-pedagógica aprofundou a compreensão da projetação como processo de gestão da informação, abrindo espaço para discussão da importância e necessidade de emprego dos fundamentos básicos, ou seja: de armazenamento, de organização e de compartilhamento de informação em ambiente computacional.

Após os MM pediu-se que os estudantes analisassem e registrassem a maneira como armazenavam, organizavam e nomeavam suas informações digitais, relativas ao curso. Prosseguindo com a apresentação e discussão dos fundamentos da gestão de informação digital, da importância da gestão eficiente para a projetação e dos problemas advindos da má gestão, estimulou-se a compreensão do processo projetual como processo de gestão da informação, segundo autores como Meniru et al (2003), Kalay (2006), Ozkaya e Akin (2006), Fabricio (2002) discutidos em Ito (2007). Debateu-se, ainda, as Diretrizes Gerais para Intercambialidade de Projetos em CAD da AsBEA (CAMBIAGHI et al, 2002), assim como o conceito e os fundamentos de Projeto Simultâneo e da Modelagem de Informação da Construção (BIM).

Em sequência, os estudantes procederam a uma sistematização de suas informações digitais relativas às disciplinas do curso, seguindo os fundamentos de gestão discutidos e inspirandose nas Diretrizes Gerais da AsBEA e na proposta do professor Aristóteles Cordeiro (1996). Esse exercício teve como objetivo sedimentar os conteúdos trabalhados e preparar para 0 exercício seguinte.

Para sedimentar os conteúdos, propôs-se que as equipes de estudantes se debruçassem sobre um "exercício-problema", cujo objetivo foi a formulação de diretrizes de gestão da informação e uso de TICs para uma empresa, um escritório ou um departamento atuante na área de arquitetura, de urbanismo, de paisagismo ou de engenharia civil. Como procedimento inicial, definiu-se a realização de um levantamento junto a empresa/escritório/departamento escolhido por cada grupo, para identificação dos procedimentos e etapas projetuais e da gestão da informação e do emprego de TICs.

Para tanto aplicou-se um questionário semiestruturado com membros da equipe de projeto, construído com base em instrumento elaborado por Ito (2007), para conhecer o processo projetual (etapas, informações geradas, responsável); procedimentos de organização, de armazenamento, de nomeação de arquivos e pastas; de emprego de arquivos padrão nos programas computacionais usados (especialmente estrutura de camadas de informação); e adoção de TICs para compartilhamento de informação.

Os dados e informações colhidos apontaram, na maioria dos locais pesquisados, para um contexto de má gestão da informação projetual, devido à ausência e/ou à carência de procedimentos básicos, como uma hierarquia lógica de pastas com nomeação pertinente. Verificou-se, também, o emprego precário de TICs para compartilhamento de informações, seja por deficiência de equipamentos, seja por pouco conhecimento dos recursos já disponíveis para essa atividade.

Com o material obtido e o suporte da bibliografia trabalhada, as equipes de estudantes foram desafiadas a elaborar diretrizes de gestão da informação e uso de TICs para solução e/ou melhoria das dificuldades identificadas na empresa/escritório/departamento objeto de investigação. A proposta de cada equipe foi entregue em forma de relatório e apresentada em seminário para toda a turma, de modo a gerar reflexão sobre semelhanças entre os problemas identificados e as soluções propostas. Além de também analisar a relação entre a gestão de informação projetual, a área de atuação e porte da instância pesquisada.

A experiência desenvolvida na disciplina foi avaliada positivamente pelos estudantes, por meio de discussão específica para esse fim, quando destacaram as dificuldades de rastreabilidade de informações com repercussões no desenvolvimento do projeto do semestre letivo. Registraram, ainda, a dificuldade no compartilhamento de informações, devido à 
maneira inadequada de nomear arquivos e registrar versão. Problemas esses que estavam sendo corrigidos por exigência quando do emprego de TICs específicas para trabalho colaborativo.

É importante assinalar a concomitância de emprego de TICs mais sofisticadas de compartilhamento de informações e mesmo de trabalho colaborativo, com a ausência de adoção de procedimentos simples e básicos de gestão de informação, como emprego de arquivos padrão com sistema de nomeação de camadas. Esse fato se verifica tanto com os estudantes quanto com empresas/escritórios/departamentos pesquisados.

A avaliação da metodologia adotada na experiência didático-pedagógica de 2012 , sinalizou a aplicabilidade de alguns princípios da pesquisa-ação, ou seja: (a) "interação entre pesquisador e sujeitos como forma de determinação de objetivos e condução da pesquisa" - atores e parceiros interessados na resolução dos problemas; (b) tem por objetivo "resolver ou, pelo menos, esclarecer os problemas da situação observada" e retroalimentar o problema experiencia como experimento; (c) "acompanha as decisões, as ações e toda a atividade dos atores da situação" - compreensão do processo como principal resultado. (THIOLENT, 1994).

A partir de 2013 a experiência foi ajustada, porém mantendo-se os exercícios. Em 2014.1 o exercício-problema foi realizado por todas as equipes na Superintendência de Projetos e Obras da universidade, o que possibilitou comparar o nível de profundidade do levantamento e as diretrizes de gestão da informação propostas. No semestre 2014.2, decidiu-se por adotar como objeto de análise e proposição o $3^{\circ}$ período do curso, considerando todas as disciplinas e suas informações, assim como a necessidade de colaboração entre estudantes de mesma equipe de projeto e de todas as equipes da turma. Essa fase da experiência didáticopedagógica será descrita a seguir.

\subsection{Aplicando fundamentos de gestão da informação no contexto do curso}

Considerando a importância de melhor articular a disciplina de InfoAU-II às demais disciplinas do período e como forma de colaborar com a interdisciplinaridade proposta pelo PPC2010, a disciplina solicitou que o aluno refletisse sobre seu processo de projeto individual e em equipe e sobre as formas utilizadas para armazenar, organizar, nomear e compartilhar as informações digitais referentes ao projeto do semestre acadêmico. Assim como nos semestres anteriores, foram elaborados MM manuais, por equipe, registrando o processo projetual do grupo e relacionando-o às disciplinas do período.

O exercício-problema passou a solicitar que as equipes de estudantes elaborassem diretrizes básicas para gestão da informação do período acadêmico em curso ( $3^{\circ}$ período), definindo plataformas de armazenamento e compartilhamento de informações digitais, estrutura de organização e de nomeação de pastas e de arquivos para todas as disciplinas, assim como arquivo-padrão dos dois programas computacionais mais utilizados (SketchUp e AutoCAD).

Para desenvolver as diretrizes, cada equipe analisou o processo adotado para realização de projetos de semestres anteriores, assim como a maneira como armazenavam, organizavam, nomeavam e compartilhavam as informações geradas pelas disciplinas do período acadêmico, especialmente as que mais interagem com a solução do problema projetual colocado pela disciplina de Projeto.

Esse procedimento de análise e discussão entre os membros da equipe, aliado aos conteúdos tratados nas aulas, embasaram a formulação da proposta de diretrizes de gestão da informação, levando em consideração o modus operandi de cada grupo.

As propostas foram entregues em relatório com justificativa das definições adotadas e socializadas em apresentação para toda a turma, possibilitando discussão e comparação das 


\section{TIC2015}

mesmas. Para exemplificar, seguem figuras da proposta das equipes 01 e 07 , consideradas mais completas e visualmente mais esclarecedoras para expor no artigo.

Figura 5 - Estrutura hieráquica de organização das pastas

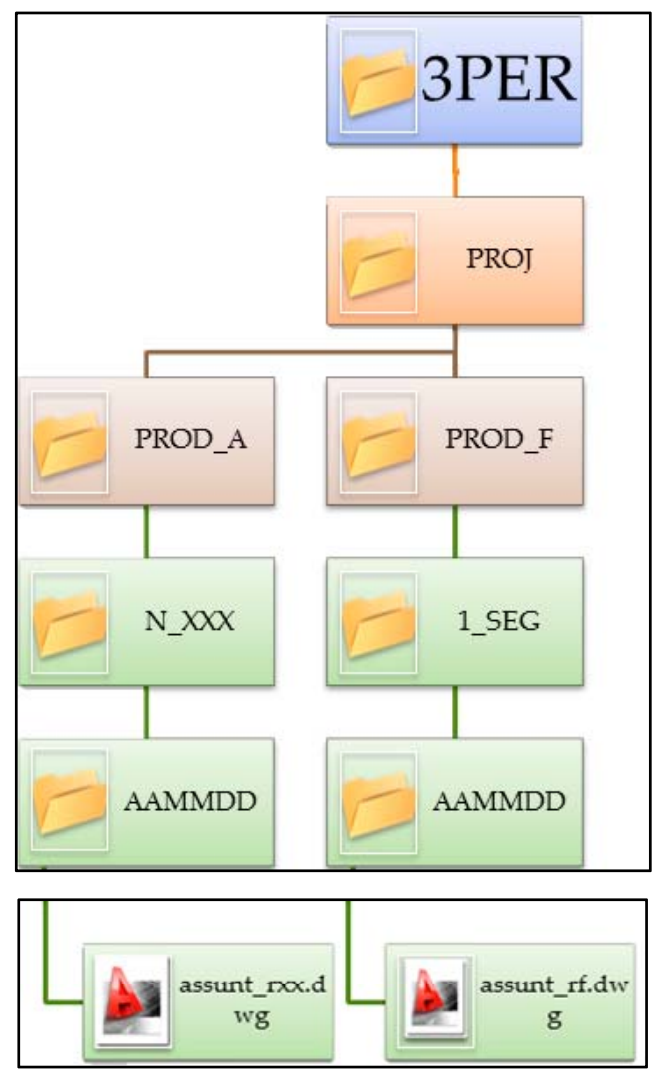

Fonte: Equipe 01 - Disciplina de InfoAU-II, 2014

Figura 6 - Exemplo de nomeação de pastas e de arquivos: de imagens e texto
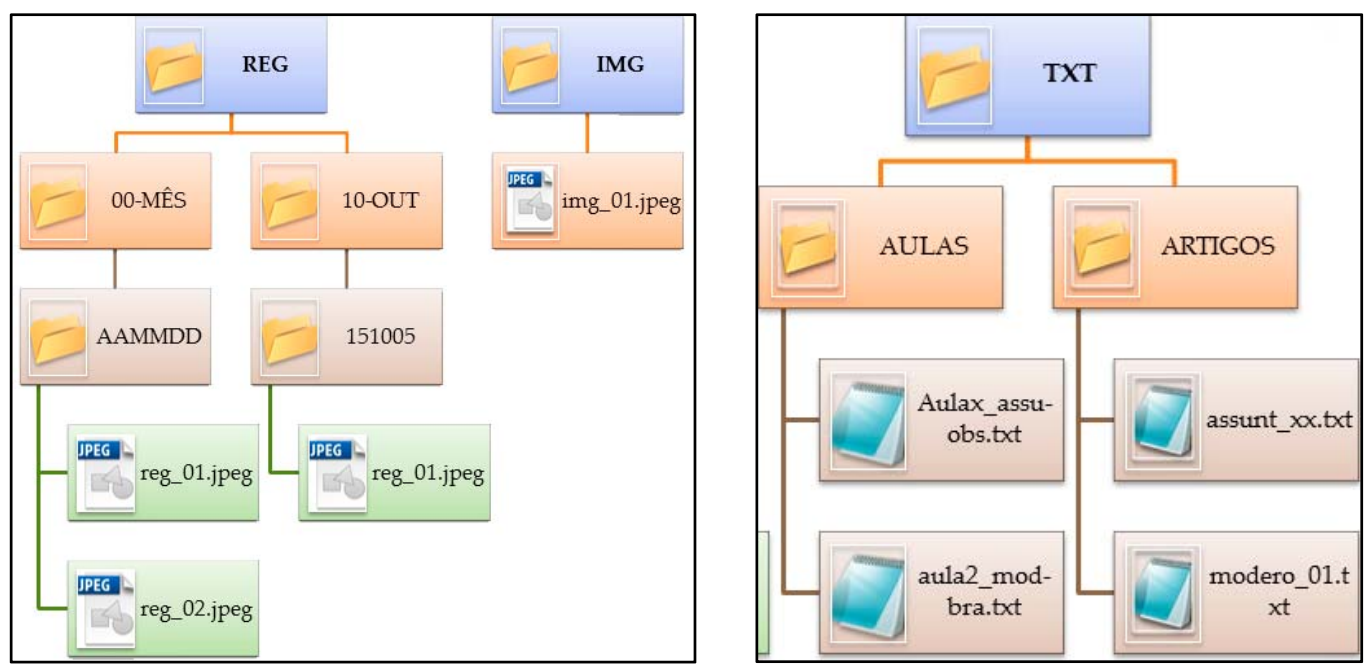

Fonte: Equipe 01 - Disciplina de InfoAU-II, 2014 
Figura 7 - Exemplo de estrutura hierárquica e nomeação de pastas e arquivos

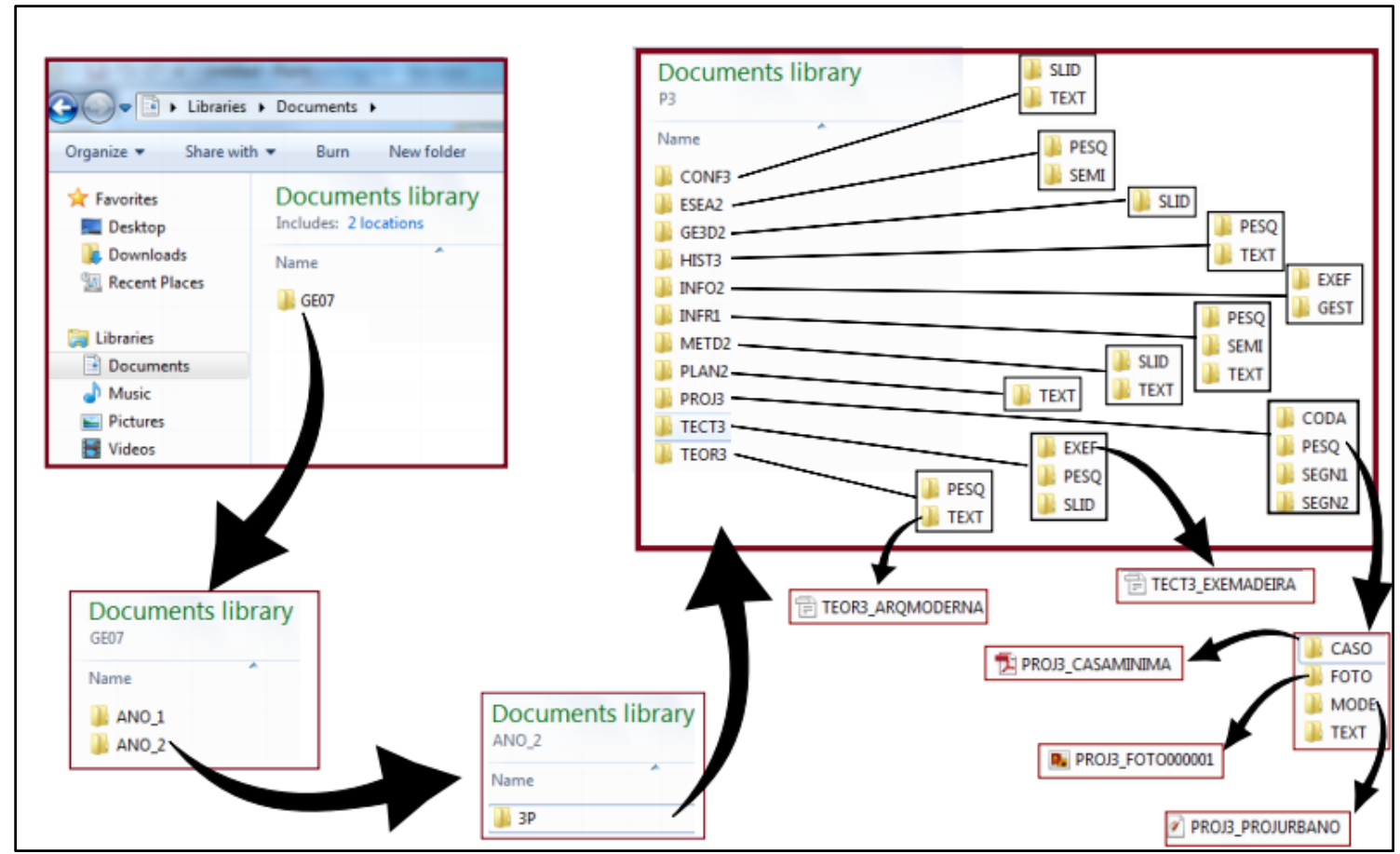

Fonte: Equipe 07 - Disciplina de InfoAU-II, 2014

As soluções propostas pelas equipes incluíram a definição das ferramentas para armazenamento e compartilhamento das informações do período, em ambiente de nuvem como Dropbox, OneDrive ou outro de preferência do grupo. Ferramentas de gestão de projetos também foram pesquisadas, visando melhor acompanhamento e controle de atividades e prazos. Entretanto, devido à carga horária da disciplina não foi possível realizar testes das mesmas e sugerir procedimentos de uso.

A experiência foi bem avaliada pelos estudantes cujos depoimentos, durante as apresentações das propostas e/ou respostas a formulários de avaliação da disciplina, registraram a mudança de procedimento na gestão da informação, com repercussão na melhoria do compartilhamento das informações projetuais entre os membros da equipe e o consequente aumento de produtividade. Por outro lado, assinalaram a dificuldade de manter o rigor nos procedimentos definidos pelas diretrizes de gestão.

Sugeriu-se que as propostas fossem apresentadas aos demais professores do período, especialmente os da disciplina de Projeto III, uma vez que os mesmos adotam o compartilhamento de informações em ambiente de nuvem, cujo acesso é permitido por todos os estudantes matriculados. Segundo os estudantes, não há organização sistematizada e padronizada no ambiente, e a adoção de diretrizes de gestão de informação ajudaria no melhor aproveitamento de todos.

\section{CONCLUSÕES}

O artigo apresentou a experiência didático-pedagógica realizada na disciplina Informática aplicada à Arquitetura, Urbanismo e Paisagismo II do Curso de Arquitetura e Urbanismo da UFPE, cujo foco foi Gestão da informação.

No contexto de implantação do novo Projeto Pedagógico de Curso - PPC2010, as três disciplinas obrigatórias da matéria de Informática aplicada à Arquitetura e Urbanismo têm procurado desenvolver conteúdos e procedimentos que potencializem a interdisciplinaridade, 
a indissociabilidade do ato projetual nas escalas da paisagem, da cidade e do edifício, e a aprendizagem baseada em problemas. Como também, de fomentar o perfil profissional do arquiteto/urbanista como gestor de processos projetuais.

Além dos resultados diretamente relacionados aos objetivos da disciplina, a experiência didático-pedagógica contribuiu para:

- a construção de procedimentos metodólogicos mais adequados à proposta do PPC2010 na matéria de InfoAU;

- a avaliação do emprego de princípios da ABP, isoladamente em uma disciplina;

- a percepção de níveis de interdisciplinaridade das disciplinas do período com a disciplina de projeto;

- a visão crítica e a capacitação dos alunos quanto ao uso de ambientes e ferramentas computacionais de projeto;

- a conscientização e reforço do perfil profissional do arquiteto/urbanista como gestor de processos projetuais pela sua instrumentalização computacional;

- a formulação de projeto de pesquisa sobre o emprego de TICs no curso, visando a potencialização da interdisciplinaridade proposta pelo PPC2010.

Considerando-se a natureza exploratória da experiência pedagógica realizada, onde a própria construção metodológica fez parte do processo, compreende-se que os resultados obtidos são suficientes e relevantes para embasar desdobramentos na matéria de InfoAU, nas outras matérias e no curso como um todo.

\section{AGRADECIMENTOS}

Aos estudantes da disciplina no período de 2012.2 a 2014.2 por aceitarem o desafio proposto e possibilitarem aprofudar reflexões e encaminhamentos sobre novas abordagens didáticopedagógicas.

\section{REFERÊNCIAS}

ALEXANDER, C. Notes on the synthesis of form. Cambridge. Massachusetts: Harvard University Press, 1964. 224 p.

ARAÚJO, U. F.; SASTRE, G. (Org) Aprendizagem baseada em problemas no ensino superior. São Paulo: Summus, 2009.

ASIMOW, M. Introduction to design. New Jersey: Prentice-Hall, 1962. 135 p.

BUSAN, T. The Mind Map Book: How to Use Radiant Thinking to Maximize Your Brain's Untapped Potential. New York: Plume, 1996. 320 p.

CAMBIAGHI, H. et al. Diretrizes gerais para intercambialidade de projetos em CAD: integração entre projetistas, construtoras e clientes. São Paulo: Pini, AsBEA, 2002.

CORDEIRO, A. L. M. O uso de sistemas CAD como instrumento de integração na produção de edifícios. João Pessoa, 1996. Dissertação (Mestrado). Centro de Tecnologia da Universidade Federal da Paraíba. 165p.

ITO, A. L. Y. Gestão da informação no processo de projeto de arquitetura: estudo de caso. 2007. Dissertação (Mestrado). Programa de Pós Graduação em Construção Civil UFPR, Curitiba, 2007.

FABRICIO, M.M. Projeto Simultâneo na Construção de Edifícios. São Paulo, 2002, 351 p. Tese (Doutorado em Engenharia). Escola Politécnica da Universidade de São Paulo.

FLÓRIO, W. Contribuições do Building Information Modeling no processo de projeto em arquitetura. In: III Encontro de Tecnologia de Informação e Comunicação na Construção Civil - TIC 2007, Porto Alegre. Disponível em: <http://noriegec.cpgec.ufrgs.br/tic2007/artigos/A1106.pdf>. Acesso em: 2 out. 2008 
JONES, J. C. Design methods: seeds of human features. New York: John Wiley \& Sons, 1970. 424 p.

KALAY, Y.E. The impact of information technology on design methods, products and practices.

Design Studies. Vol. 27, n.3, p. 357-380, maio, 2006. Disponível em:

<http://www.sciencedirect.com/science> Acesso em: 4 ago. 2006.

MELHADO, S. B. Gestão, Cooperação e Integração para um Novo Modelo Voltado à

Qualidade do Processo de Projeto na Construção de Edifícios. 2001. Tese (Livre Docência).

Escola Politécnica da Universidade de São Paulo, São Paulo, 2001.

MENIRU, K.; RIVARD, H.; BE'DARD, C. Specifications for computer-aided conceptual building design. Design Studies. Vol. 24, n. 1, p. 51-71, jan. 2003. Disponível em:

<http://www.sciencedirect.com/science> Acesso em: 04 ago. 2006.

NEWELL, A.; SIMON, H. A. Human problem solving. Londres: Prentice-Hall, 1972. p. 1-15; p. 869872.

MITCHELL, W. A lógica da arquitetura: projeto, computação e cognição. Campinas: UNICAMP, 2008. 304p.

OZKAYA, I.; AKIN, Ö. Requirement-driven design: assistance for information traceability in design computing. Design Studies. Vol. 27, n. 3, p. 381-398, maio, 2006. Disponível em:

<http://www.sciencedirect.com/science> Acesso em: 04 ago. 2006.

PORTO CARREIRO, P.; RÊGO, R. M. Novas práticas pedagógicas da matéria de Informática aplicada à Arquitetura, Urbanismo e Paisagismo: Experimentações dentro do Novo Currículo do Curso de Arquitetura e Urbanismo/UFPE. In: XXXIII ENSEA/ XXXVI COSU: O Ensino de Arquitetura e Urbanismo: Teoria e Prática. ABEA, 39, 2014, Balneário Camboriú/SC. Anais... Balneário Camboriú/SC: UNIVALI/ASBEA, p.224-242.

RÊGO, R M. Educação gráfica e projetação arquitetônica - as relações entre a capacidade visuográfica tridimensional e a utilização da modelagem geométrica 3D. São Paulo: Edgard Blücher, 2011.

SCHÖN, D. A. The Reflective Practitioner - how professionals think in action. EUA: Basic Books, 1983. $374 \mathrm{p}$

SCHÖN, D. A. Educando o Profissional Reflexivo - um novo design para o ensino e a aprendizagem. Trad. Roberto Cataldo Costa. Porto Alegre: Artes Médicas Sul, 2000. 256 p.

SIMON, H. A. The sciences of the artificial. Cambridge: MIT Press, 1969.

THIOLENT, M. Metodologia da pesquisa-ação. São Paulo: Cortez,1994. 